OPEN ACCESS

Edited by:

Deanne Helena Hryciw, Griffith University, Australia

Reviewed by: Jessica Griffith,

The University of Melbourne, Australia Nirajan Shrestha,

Griffith University, Australia

${ }^{*}$ Correspondence:

Shujun Jiang

fairyjsj@163.com

Pingxi Xiao

xpx@njmu.edu.cn

Shi-Ping Ma

spma@cpu.edu.cn

${ }^{\dagger}$ These authors have contributed equally to this work

Specialty section:

This article was submitted to

Obesity,

a section of the journal

Frontiers in Endocrinology

Received: 12 February 2020 Accepted: 08 September 2020

Published: 06 October 2020

Citation:

Shi N, Liu K, Fan Y, Yang L, Zhang S, LiX, Wu H, LiM, Mao H, XuX, MaS-P,

Xiao $P$ and Jiang $S$ (2020)

The Association Between Obesity and Risk of Acute Kidney Injury After Cardiac Surgery.

Front. Endocrinol. 11:534294. doi: 10.3389/fendo.2020.534294

\section{The Association Between Obesity and Risk of Acute Kidney Injury After Cardiac Surgery}

\author{
Ning Shi ${ }^{1,2 \dagger}$, Kang Liu ${ }^{3 \dagger}$, Yuanming Fan ${ }^{1,2 \dagger}$, Lulu Yang ${ }^{1,2}$, Song Zhang ${ }^{1,2}, \mathrm{Xu} \mathrm{Li}^{1,2}$, \\ Hanzhang $\mathrm{Wu}^{3}$, Meiyuan $\mathrm{Li}^{3}$, Huijuan $\mathrm{Mao}^{3}$, Xueqiang $\mathrm{Xu}^{3}$, Shi-Ping Ma ${ }^{2 *}$, Pingxi Xiao ${ }^{4 *}$ \\ and Shujun Jiang ${ }^{1,5 *}$ \\ ${ }^{1}$ Clinical Metabolomics Center, China Pharmaceutical University, Nanjing, China, ${ }^{2}$ State Key Laboratory of Natural \\ Medicines, China Pharmaceutical University, Nanjing, China, ${ }^{3}$ Department of Nephrology, Jiangsu Province Hospital, \\ Nanjing, China, ${ }^{4}$ Department of Cardiology, The Affiliated Sir Run Run Hospital of Nanjing Medical University, Nanjing, China, \\ ${ }^{5}$ Department of Infectious Diseases, Nanjing Hospital of Chinese Medicine Affiliated to Nanjing University of Chinese \\ Medicine, Nanjing, China
}

Objective: To determine the relationship between obesity and the risk of AKI after cardiac surgery (CS-AKI) in a cohort study.

Methods: A total of 1,601 patients undergoing cardiac surgery were collected and their incidence of CS-AKI was recorded. They were divided into underweight, normal weight, overweight, and obese groups. Logistic regression was used to estimate the association between BMI (body mass index) and CS-AKI risk. Then, a meta-analysis of published cohort studies was conducted to confirm this result using PubMed and Embase databases.

Results: A significant association was observed in this independent cohort after adjusting age, gender, hypertension and New York Heart Association classification (NYHA) class. Compared with normal BMl group (18.5 $\leq \mathrm{BMl}<24.0)$, the individuals with aberrant BMl level had an increased AKI risk (OR: 1.68, 95\% Cl: 1.01-2.78) for $\mathrm{BMl}<18.5$ group and (OR: $1.43,95 \% \mathrm{Cl}: 0.96-2.15)$ for $\mathrm{BMI} \geq 28.0$. Interestingly, the U-shape curve showed the $\mathrm{CS}-\mathrm{AKI}$ risk reduced with the increasing of $\mathrm{BMI}$ when $\mathrm{BMI} \leq 24.0$. As $\mathrm{BMI}$ increases with $\mathrm{BMI}>24.0$, the risk of developing CS-AKI increased significantly. In the confirmed meta-analysis, compared with normal weight, overweight group with cardiac surgery had higher AKI risk (OR: 1.28, 95\% Cl: 1.16-1.41, $P_{\text {heterogeneity }}=0.49$ ). The similar association was found in obesity subgroup (OR: $1.79,95 \% \mathrm{Cl}: 1.57-2.03, P_{\text {heterogeneity }}=0.42$ ).

Conclusion: In conclusion, the results suggested that abnormal BMI was a risk factor for CS-AKI independently.

Keywords: obesity, body mass index, acute kidney injury, cardiac surgery, creatinine 


\section{INTRODUCTION}

Acute kidney injury (AKI) is a multifactorial, complicated, heterogeneous clinical syndrome characterized by a sudden decrease of renal function. It is considered to be one of the most common serious complications after cardiac surgery (1), which not only prolongs hospitalization, but also increases the risk of death (2-5). About $18 \%$ of patients undergoing cardiac surgery develop AKI, and between $2 \%$ and $6 \%$ need renal replacement therapy (6). More than 2 million patients worldwide undergo cardiac surgery annually, while the incidence of post-cardiac surgery AKI (CS-AKI) varies from $5 \%$ to $42 \%(7,8)$. CS-AKI results from reduced renal perfusion which in turn results from post-cardiac surgery vasoconstriction or ischemia-reperfusion injury that occurs in the extracorporeal circulation (9).

Obesity is an increasingly relevant medical and socioeconomic problem in developed and developing countries (10). According to the World Health Organization (11), adults with body mass index $(\mathrm{BMI}) \geq 25.0 \mathrm{~kg} / \mathrm{m}^{2}$ and $\geq 30.0 \mathrm{~kg} / \mathrm{m}^{2}$ are defined as overweight and obese, respectively. Cardiac patients with excessive BMI are at an increased risk of AKI, owing to their disproportionately higher burden of comorbidities and underlying structural changes that occur in the kidneys of obese patients in spite of normal serum chemistry (12). Obesity is reported to be associated with AKI for patients under intensive care, post-operative populations (13-15) and obese patients after surgery with AKI exhibited the increase of oxidative stress, endothelial dysfunction and inflammation (16, 17). However, another study found no correlation between obesity and increased risk of major perioperative complications after transcatheter aortic valve implantation (18). Thus, the association between CS-AKI and obesity remains questionable.

Herein, we recruited CS-AKI patients and performed a prospective cohort study to determine the association between obesity and CS-AKI. Thereafter, a meta-analysis was conducted to confirm or otherwise our findings.

\section{METHODS AND MATERIAL}

\section{Clinical Study Population}

Blood samples from participants undergoing cardiac surgery were collected at the Jiangsu Province hospital. The BMI classification followed the standards established for Chinese by the Department of Disease Control, Ministry of Health (19). Patients $(\mathrm{n}=1,601)$ were divided into four groups: underweight $(\mathrm{BMI}<18.5, \mathrm{n}=98)$; normal-weight $(18.5 \leq \mathrm{BMI}<24.0, \mathrm{n}=799)$; overweight $(24.0 \leq$ $\mathrm{BMI}<28.0, \mathrm{n}=539)$; and obese (BMI $\geq 28.0, \mathrm{n}=165$ ) groups. AKI was defined in accordance with the guidance of the Kidney Disease Improving Global Outcomes (KDIGO) (19), thus: (1) increase in serum creatinine by $\geq 0.3 \mathrm{mg} / \mathrm{dl}(\geq 26.5 \mu \mathrm{mol} / \mathrm{L})$ within $48 \mathrm{~h}$; (2) increase in serum creatinine to $\geq 1.5$ times baseline, which is known or presumed to have occurred within previous 7 days; (3) urine volume $<0.5 \mathrm{ml} / \mathrm{kg} / \mathrm{h}$ for $6 \mathrm{~h}$ and staged according to the serum creatinine and urine output. The preoperative general information of all patients was collected. A detailed clinical history was obtained from the patient and the family, including gender, age, smoking history, history of disease (hypertension, diabetes, hyperlipidemia). Blood biochemical indices were measured with Biochemical Analyzer (BECKMAN COULTER AU5800, Japan), in which the creatinine was detected by the enzymatic method with creatininase coupled sarcosine oxidase method. All medical laboratory data were generated by the clinical laboratory of Jiangsu Province hospital.

All participants provided written informed consent at the time of enrollment. The inclusion/exclusion criteria are described as following, for inclusion criteria: (1) Patients who have undergone cardiac surgery; (2) AKI was determined by inhospital examination; (3) Informed consent was signed. For exclusion criteria: (1) Patients with elevated creatinine before operation or those were diagnosed as severe renal insufficiency before operation; (2) Patients with chronic kidney disease, kidney surgery or kidney transplantation; (3) Patients with malignant tumor, autoimmune disease, severe infection and trauma. This study complied with the Helsinki Declaration.

The perioperative standard management, coronary angiography, anesthesia and surgical techniques were performed in all patients, and the operation and cardiopulmonary bypass were performed by the same professional team. American society of anesthesiologist classification, blood gas analysis, intraoperative medication, intraoperative fluid output, operation time, cardiopulmonary bypass time, aortic block time and cardiac arrest time were monitored during surgery.

All patients were transferred to the intensive care unit (ICU) after operation, and laboratory indicators will be standard monitored all the time. After 24-48 hours of routine treatment, the patients can be transferred to the cardio vascular ward. All enrolled patients avoided the use of potentially nephrotoxic drugs during hospitalization.

\section{Search Strategy and Selection Criteria}

Studies published up to 1 December 2018 were searched for in PubMed and Embase databases using the following key words: (acute kidney injury) AND (obesity), (acute kidney injury) AND (BMI). All titles and abstracts of studies retrieved were reviewed to select potentially eligible studies. Full texts of potentially eligible publications were reviewed by all investigators. Discrepancies were reconciled through discussion by the reviewers who extracted the data and, if these remained unresolved, the other authors were involved in arriving at a resolution. Our outcome was limited to CS-AKI by any of these definitions. The references of the articles that satisfied the inclusion criteria were also involved, and duplicated studies were excluded.

The inclusion criteria are described here: (1) studies confirmed to be cohort; (2) studies that set BMI, obesity or weight the exposure factor(s); (3) articles describing the occurrence of CS-AKI; (4) studies that provided the value of events with Odds Ratio (OR) and 95\% Confidence Interval (CI).

\section{Data Extraction}

We extracted the following information from each study: first author's surname, publication year, study location, study period, sample size, sample source, AKI diagnostic criteria, BMI, BMI 
categories, risk estimates with the corresponding 95\% CIs for each BMI category, and adjustment factors in the multivariable analysis. The BMI $\left(\mathrm{kg} / \mathrm{m}^{2}\right)$ for adults of European and American decent was classified as follows: normal weight, 18.5 or 20.0-25.0; overweight, 25.0-30.0 and obesity $\geq 30.0$ (using the standards of the World Health Organization). One study from China used BMI classification established for Chinese, hence, underweight < 18.5; normal-weight 18.5-24.0; overweight 24.0-28.0; obesity BMI $\geq 28.0$ (20). We assigned the midpoint of the upper and lower boundaries in each category as the average level. Data were extracted independently according to the selection criteria.

\section{Statistical Analysis}

Categorical data were shown as percentage, while continuous data were provided as mean $\pm \mathrm{SD}$. The normal weight group was regarded as reference category in the study. Cohort logistic regression was used to estimate the association between BMI and CS-AKI, and odd ratio and 95\% CI were reported. We adjusted for covariates that have been used in previous studies for prediction of CS-AKI, including patient demographics (age, sex) and medical history (hypertension, NYHA class). Categorical variables were compared with chi-square test while predictors of CS-AKI were identified with logistic regression analysis.

For the meta-analysis, combined OR was used to measure the association between obesity and CS-AKI risk. Stratification of meta-analysis was conducted for different levels of BMI. Data were analyzed using a random-effects model. To investigate the effect of potential confounders, subgroup analyses were conducted using the available characteristics of studies and participants, if three or more studies were available per subgroup.

The $Q$ and $I^{2}$ statistics were used to assess heterogeneity among studies. To explore the possible heterogeneity among different studies, AKI diagnostic criteria, study locations, and adjustments for confounding factors, a meta-regression model was used. Considering the possibility of effect modification by other known risk factors (i.e., sex, age, smoking, and hypertension), we also conducted dose-response meta-analyses by these factors respectively apart from subgroup analyses. Sensitivity analysis was used to evaluate the influence of a single study on the entire result by omitting each study in sequence. Publication bias was evaluated with Begg's funnel plots and the Egger's test.

All statistical analyses of clinical information were performed with R 3.5.1. All tests were two-sided and $p<0.05$ was considered statistically significant.

\section{RESULTS}

\section{Patients' Characteristics}

A total of 1,601 cardiac surgery patients were recruited from the Jiangsu Province hospital for this study. Baseline characteristics and laboratory data are shown in Table 1. In detail, there were 318 AKI patients and 1,283 controls. Age, gender, comorbid conditions (diabetes, hypertension, and hyperlipemia), previous surgical history, smoking, New York Heart Association classification (NYHA) class, and coronary angiography (CAG) are provided.
TABLE 1 | Baseline characteristics of subjects.

\begin{tabular}{|c|c|c|c|}
\hline & $A K I(n=318)$ & Non-AKI $(n=1,283)$ & $P$ value \\
\hline Male (\%) & $187(58.91)$ & $649(50.58)$ & 0.009 \\
\hline Age (mean \pm SD) & $56.92 \pm 11.40$ & $53.57 \pm 13.58$ & 0.001 \\
\hline \multicolumn{4}{|l|}{ BMI (\%) } \\
\hline BMI < $18.5(n=98)$ & $24(7.55)$ & $74(5.77)$ & 0.658 \\
\hline $18.5 \leq \mathrm{BMI}<24(\mathrm{n}=799)$ & $150(47.17)$ & 649(50.58) & 0.229 \\
\hline $24 \leq B M I<28(n=539)$ & 103(32.39) & 436(33.98) & 0.298 \\
\hline BMI $\geq 28(n=165)$ & $41(12.89)$ & 124(9.66) & 0.045 \\
\hline \multicolumn{4}{|l|}{ Medical history } \\
\hline Diabetes (\%) & $52(16.35)$ & $170(13.25)$ & 0.152 \\
\hline Hypertension (\%) & $146(45.91)$ & 433(33.75) & $<0.001$ \\
\hline Hyperlipemia (\%) & $80(25.16)$ & 268(20.89) & 0.099 \\
\hline Previous Surgery history (\%) & $145(45.60)$ & 531(41.39) & 0.174 \\
\hline Smoking (\%) & $90(28.30)$ & 303(23.62) & 0.082 \\
\hline \multicolumn{4}{|l|}{ NYHA class (\%) } \\
\hline I & 29(9.12) & 168(13.09) & 0.053 \\
\hline II & $73(22.96)$ & 424(33.05)) & $<0.001$ \\
\hline III & 189(59.43) & $612(47.70)$ & $<0.001$ \\
\hline IV & $27(8.49)$ & $79(6.16)$ & 0.134 \\
\hline CAG (\%) & $141(44.34)$ & $494(38.50)$ & 0.057 \\
\hline
\end{tabular}

BMI, body mass index; NYHA, New York Heart Association (classification); CAG: coronary arteriongraphy; AKI, acute kidney injury.

The percentage of males was higher among AKI patients than in non-AKI subjects. As for patients' post-cardiac surgery, AKI group was older and exhibited higher percentage of hypertension and hyperlipemia than non-AKI patients. The NYHA class showed significant differences between AKI and non-AKI patients. In addition, more AKI subjects suffered from CAG than those in the non-AKI group.

With respect to $\mathrm{BMI}$, there were $24 \mathrm{AKI}$ patients in the underweight group (BMI $<18.5, \mathrm{n}=98$ ), 150 AKI patients in the normal weight group $(18.5 \leq \mathrm{BMI}<24.0, \mathrm{n}=799), 103$ patients in the overweight group $(24.0 \leq \mathrm{BMI}<28.0, \mathrm{n}=539)$, and 95 patients in the obese group ( $\mathrm{BMI} \geq 28.0, \mathrm{n}=95)$. The incidence of AKI was $24.49 \%$ for the underweight group, $18.77 \%$ for the normal weight group, $19.11 \%$ for the overweight group, and $24.85 \%$ for the obese group.

\section{The Association Between BMI and CS-AKI}

To estimate the relationship between BMI and CS-AKI risk, a logistic regression was conducted. A significant association was observed in this independent cohort after adjusting for age, gender, hypertension and NYHA class. As shown in Table 2, compared with normal BMI group $(18.5 \leq \mathrm{BMI}<24.0)$, the individuals with aberrant BMI level had an increased AKI risk (OR: 1.68, 95\% CI: 1.01-2.78) for BMI < 18.5 group and (OR: 1.43,

TABLE 2 | The association between BMI and AKI.

\begin{tabular}{lcccc}
\hline Group & AKI & Non-AKI & OR $\mathbf{( 9 5 \% \mathbf { C l } )}$ & $\boldsymbol{P}$ value \\
\hline BMI $<\mathbf{1 8 . 5 0}$ & 24 & 74 & $1.68(1.01-2.78)$ & 0.045 \\
$\mathbf{1 8 . 5 0} \leq \mathbf{B M I}<\mathbf{2 4 . 0}$ & 150 & 649 & 1.00 & 1.00 \\
$\mathbf{2 4 . 0} \leq \mathbf{B M I}<\mathbf{2 8 . 0}$ & 103 & 436 & $0.93(0.70-1.24)$ & 0.62 \\
$\mathbf{B M I} \geq \mathbf{2 8 . 0}$ & 41 & 124 & $1.43(0.96-2.15)$ & 0.08 \\
\hline
\end{tabular}

OR, Odds ratios represent BMI increases adjusted for age, gender, hypertension and NYHA class.

BMI, body mass index; NYHA, New York Heart Association (classification). 
95\% CI: 0.96-2.15) for BMI > 28.0. Interestingly, the U-shape curve showed the CS-AKI risk reduced with increasing BMI (at BMI $\leq 24.00)$. As BMI increased beyond 24.0, the risk of developing CS-AKI increased significantly (Figure 1).

Stratified analyses performed according to BMI shown in Table 3, age, hypertension, and NYHA class were significantly associated with the risk of CS-AKI after adjusting age, gender, hypertension and NYHA class these factors (Table 3). The frequency of hypertension was positively associated with BMI increase.

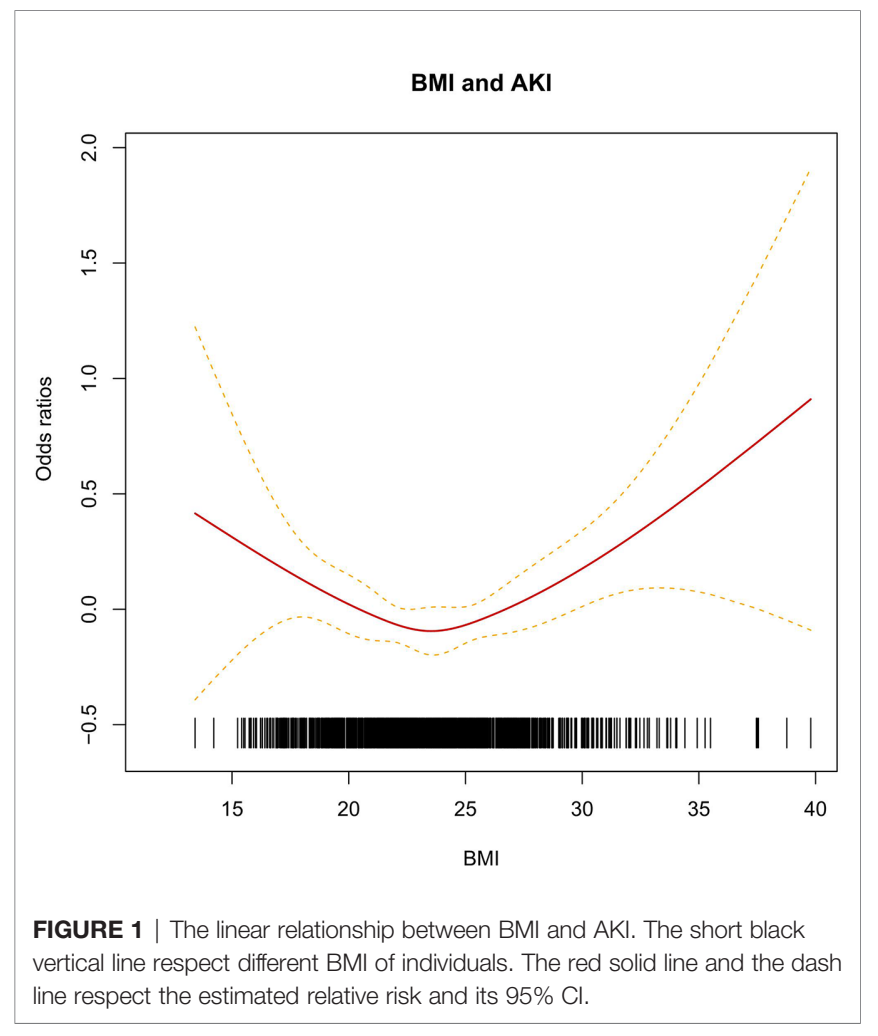

\section{Literature Search and Study Characteristics of Meta-Analysis}

To further confirm the association between BMI and AKI risk, a meta-analysis was performed. A flowchart of this is shown in Supplementary Figure 1. The initial search of literature identified 768 unique studies, of which 705 were excluded. After carefully reviewing the full textual content of prospective studies, seven articles were finally used $(18,21-26)$. The characteristics of these studies are presented in Supplementary Table 1. In detail, three AKI diagnostic criteria were applied to these studies as following: three studies used AKIN criteria, two studies used RIFLE criteria, one study used KDIGO criteria and one study unknown. These studies were representative of four regions, namely USA, UK, Europe (including Italy, France, and The Netherlands) and China. The sample size ranged from 376 to 8,455 , and the AKI cases ranged from 26 to 2,855.

\section{Quantitative Synthesis and Subgroup Analysis by Meta-Analysis}

Compared with normal weight, overweight group with cardiac surgery had higher AKI risk. A similar association was found in obese subgroup (OR: 1.79, 95\% CI: 1.57-2.03) (Figure 2A).The combined ORs (95\% CI) were $1.28(1.16-1.41)$ (Figure 2B). The heterogeneity among the studies were low $\left(I^{2}=0.0 \%\right.$ for overweight, $I^{2}=0.7 \%$ for obese groups) (Supplementary Table 2).

When stratified by Geographic area, as shown in Supplementary Table 2, there was a higher AKI risk in UK and China for overweight and obese groups in relation to the normal weight group. In the stratified analysis by diagnosis standard, the overweight subjects diagnosed using the KDIGO standard suffered from increased AKI risk compared to those with normal weight. When stratified by Geographic area, as shown in Supplementary Table 2, there was a higher AKI risk in UK and China for overweight and obesity groups compared with normal weight individuals. In the stratified analysis by diagnosis standard, the subjects with KDIGO diagnosis standard suffered

TABLE 3 | Subgroup analysis of clinical characteristics according to BMI.

\begin{tabular}{|c|c|c|c|c|c|c|}
\hline & $B M I<18.5(n=98)$ & $18.5 \leq B M I<24(n=799)$ & $24 \leq B M I<28(n=539)$ & $B M I \geq 28(n=165)$ & All & $P$ value \\
\hline Male (\%) & 32 (32.65) & $382(47.81)$ & 327 (60.67) & $95(57.58)$ & 836 (52.22) & 0.141 \\
\hline Age (mean $\pm S D$ ) & $46.69 \pm 16.37$ & $53.00 \pm 13.73$ & $57.00 \pm 11.61$ & $55.00 \pm 11.48$ & $54.00 \pm 13.24$ & 0.030 \\
\hline BMI (mean $\pm S D)$ & $17.22 \pm 0.95$ & $21.61 \pm 1.50$ & $25.68 \pm 1.14$ & $30.35 \pm 2.20$ & $23.61 \pm 13.56$ & 0.001 \\
\hline \multicolumn{7}{|l|}{ Medical history } \\
\hline Diabetes (\%) & $4(4.08)$ & $64(8.01)$ & 106 (19.67) & 37 (22.42) & $211(13.18)$ & 0.841 \\
\hline Hypertension (\%) & $15(15.31)$ & $45(5.63)$ & 207 (38.40) & $86(52.12)$ & 353 (22.05) & 0.008 \\
\hline Hyperlipemia (\%) & $14(14.29)$ & $145(18.15)$ & $134(24.86)$ & 55 (33.33) & $348(21.74)$ & 0.962 \\
\hline \multicolumn{7}{|l|}{ Previous surgery } \\
\hline history (\%) & $23(23.47)$ & $169(21.15)$ & 268 (49.72) & $80(48.48)$ & 540 (33.73) & 0.201 \\
\hline Smoking (\%) & $12(12.24)$ & 160 (20.03) & $150(27.83)$ & $51(30.91)$ & 373 (23.30) & 0.923 \\
\hline NYHA class (\%) & & & & & & $<0.001$ \\
\hline I & $13(13.27)$ & 87 (10.89) & 99(18.37) & 17 (10.30) & $136(8.49)$ & \\
\hline II & $25(25.51)$ & 250 (31.29) & $180(33.40)$ & $47(28.48)$ & 502 (31.36) & \\
\hline III & $54(55.10)$ & 429 (53.69) & 235 (43.60) & $84(50.91)$ & 802 (50.09) & \\
\hline IV & $6(6.12)$ & $33(4.13)$ & $25(4.64)$ & 17 (10.20) & $81(5.06)$ & \\
\hline CAG (\%) & $21(21.43)$ & 278 (34.79) & $258(47.87)$ & $78(47.27)$ & 635 (39.66) & 0.255 \\
\hline AKI (\%) & 24 (24.49) & $150(18.77)$ & 103 (19.11) & $41(24.85)$ & 318 (19.86) & 0.147 \\
\hline
\end{tabular}

BMI, body mass index; NYHA, New York Heart Association (classification); CAG: coronary arteriongraphy; AKI, acute kidney injury. 

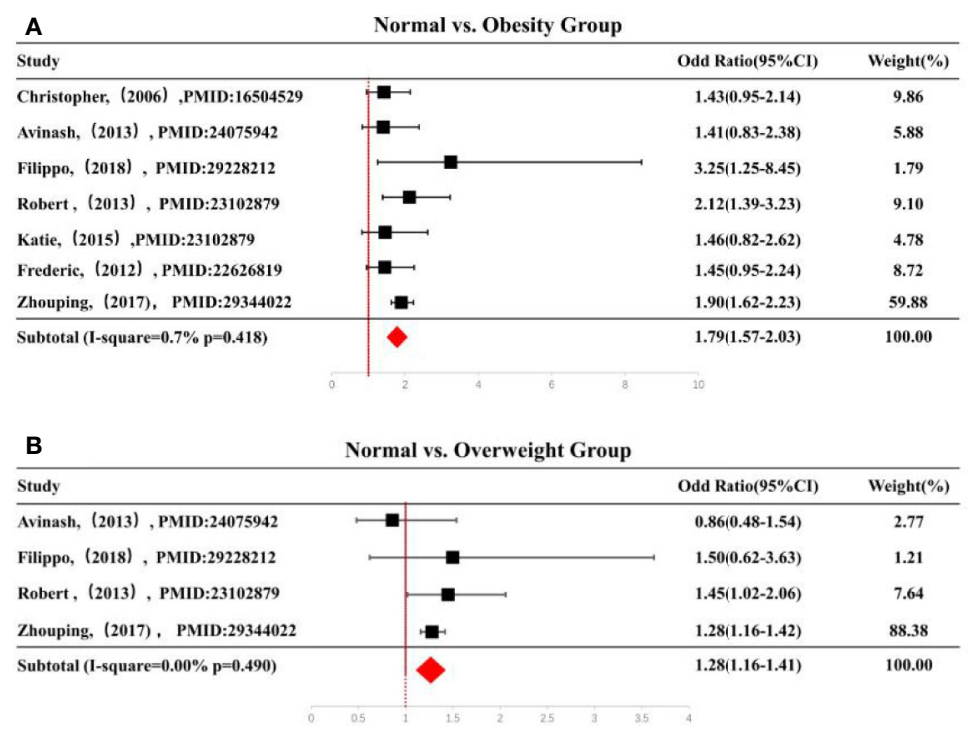

FIGURE 2 | (A) Forest plot of ORs of obesity vs. normal weight and (B) forest plot of ORs of overweight vs. normal weight. Black squares indicate the OR in each study, horizontal lines represent the $95 \% \mathrm{Cl}$. OR, odd ratio; Cl, confidence interval; BMI, body mass index.

from increased AKI risk for overweight compared with normal weight. In addition, age, hypertension, diabetes and smoking were also significantly related to AKI risk for overweight and obesity subgroup compared with normal weight. Both the funnel plot and Egger's test showed no publication bias (Supplementary Figure 2).

\section{DISCUSSION}

In this cohort study, we recruited 1,601 individuals post-cardiac surgery. We found overweightness to be an independent risk factor of CS-AKI. The outcome of the meta-analysis further confirmed the correlation between overweightness and obesity and increased incidence of CS-AKI. Similar results were observed in the subgroup analysis by geographic area and AKI diagnostic standard.

In line with our results, previous studies reported BMI as an independent risk factor of CS-AKI. For instance, Ko and colleagues demonstrated that high BMI was an independent risk factor of AKI (27). Also, there was no significant correlation between BMI and renal insufficiency in elderly patients undergoing coronary artery bypass grafting from the findings by Reis et al. (28). Roh and colleagues reported that age and BMI were not independent risk factors for CS-AKI (29). Another study reported that extreme obesity $\left(\mathrm{BMI}>40 \mathrm{~kg} / \mathrm{m}^{2}\right)$ was associated with AKI, rather than obesity (BMI, 30-40 kg/m²) (24). These divergent conclusions perhaps stemmed from differences in AKI diagnostic criteria, differences in geographical regions of study, dissimilarities in patient inclusion criteria, and different adjustment for identified AKI risk factors.

With the increasing incidence of CS-AKI $(30,31)$, the role of abnormal BMI in AKI has drawn more and more attention in the world, but the deeply mechanism is still unclear. Obesity can significantly alter renal hemodynamics, which may explain the increased susceptibility of obese patients to AKI (32). Increased renal plasma flow and glomerular filtration rate due to hemodynamic changes may lead to higher filtration rate or high filtration syndrome, making the kidneys prone to damage (33). In addition, obese patients often suffer from cor-pulmonale due to insufficient ventilation, sleep apnea and pulmonary hypertension leading to sodium dependence and peripheral venous congestion $(34,35)$. It also has been reported that peripheral venous congestion in turn could result in increased renal venous pressure, thereby reducing urine formation (36). Another factor contributing to the effect of obesity on AKI is the challenge of correctly assessing the status of vascular content and adequate fluid therapy. Obesity shows influence on the dosage of potential nephrotoxic drugs via affecting many pharmacokinetic factors (37).

Of note, obese ICU patients have an increased risk of elevated intra-abdominal pressure, which could lead to renal insufficiency due to venous congestion and poor perfusion of arterial organs $(38,39)$. In addition, obesity-related cardiac changes such as increased left ventricular hypertrophy and direct myocardial infiltration may also alter renal perfusion (40).

The term "obesity paradox" has been used to describe similar or improved survival rates in critically-ill obese patients. One explanation for this phenomenon is that obese patients benefit from metabolic or nutritional reserves, which ultimately leads to increased survival under diseased conditions (41). A multicenter observational study of 940 patients found no link between obesity (BMI > $30 \mathrm{~kg} / \mathrm{m}^{2}$ ) and increased risk of major perioperative complications during trans-catheter aortic valve implementation. However, obese patients had a greater incidence of CS-AKI (stage I). In this study, a clear association between increased operative mortality and increased BMI was found, thereby refuting the "obesity paradox" for operative outcomes. 
Conflicting findings of previous studies could be due to differences in patient cohort, risk stratification and BMI classification (42-44). In a contemporary multi-agency regional cohort study of 13,637 patients, researchers showed that increased BMI significantly elevated the likelihood of major post-operative morbidities, especially acute renal failure and pneumonia (45).

Metabolic syndrome (MetS) has been reported as a risk factor for postoperative kidney injury after off-pump coronary artery bypass surgery (OPCAB) (46). But our study show that there is no significant difference in the effect of diabetes $(p=0.152)$ and hyperlipemia $(\mathrm{p}=0.099)$ on CS-AKI, small sample size may be relevant with this conclusion. Conclusively, Future work with larger sample size, especially the diabetes and hyperlipemia patients are needed. The relationship between hyperlipemia and CS-AKI still needs to be studied in future studies with a larger multi-center sample. Previous report revealed that of mean arterial pressure (MAP) is a risk factor for the progression of AKI (47). Continued high blood pressure produces increased vascular hydrostatic pressure with consequent thickening of arterial wall. The alterations make the kidney more prone to develop pre-renal AKI in case of hypo-perfusion (48). Consistent with this view, our study confirmed that patients with hypertension medication history had higher risk of CS-AKI than their counterparts.

The limitations of this study are herein outlined: First, although the surgery principles governing conduct with respect to patient are the same, there are still differences in surgical operation on the details. It's hard to eliminate the impact of surgical procedures on the incidence of AKI. Second, samples undergoing cardiac surgery were recruited from a single center, which perhaps introduced bias to the result.

In conclusion, our findings are consistent with the generally held consensus that abnormal BMI is an independent risk factor for the development of CS-AKI. Patients whose BMI were below 18.5 or above 28.0 had a higher incidence of CS-AKI in our cohort study. BMIs > 18.5 were independent predictors of CS-AKI.

\section{REFERENCES}

1. Kellum JA, Prowle JR. Paradigms of acute kidney injury in the intensive care setting. Nat Rev Nephrol (2018) 14(4):217-30. doi: 10.1038/nrneph.2017.184

2. Kork F, Balzer F, Spies CD, Wernecke KD, Ginde AA, Jankowski J, et al. Minor Postoperative Increases of Creatinine Are Associated with Higher Mortality and Longer Hospital Length of Stay in Surgical Patients. Anesthesiology (2015) 123(6):1301-11. doi: 10.1097/ALN.0000000000000891

3. Grams ME, Sang Y, Coresh J, Ballew SH, Matsushita K, Levey AS, et al. Candidate Surrogate End Points for ESRD after AKI. J Am Soc Nephrol JASN (2016) 27(9):2851-9. doi: 10.1681/ASN.2015070829

4. O'Connor ME, Hewson RW, Kirwan CJ, Ackland GL, Pearse RM, Prowle JR. Acute kidney injury and mortality 1 year after major non-cardiac surgery. $\mathrm{Br} J$ Surgery (2017) 104(7):868-76. doi: 10.1002/bjs.10498

5. O'Connor ME, Kirwan CJ, Pearse RM, Prowle JR. Incidence and associations of acute kidney injury after major abdominal surgery. Intensive Care Med (2016) 42(4):521-30. doi: 10.1007/s00134-015-4157-7

6. Thiele RH, Isbell JM, Rosner MH. AKI associated with cardiac surgery. Clin J Am Soc Nephrol CJASN (2015) 10(3):500-14. doi: 10.2215/CJN.07830814

7. Weisse $\mathrm{AB}$. Cardiac surgery: a century of progress. Texas Heart Institute J (2011) 38(5):486-90.

\section{DATA AVAILABILITY STATEMENT}

All datasets generated for this study are included in the article/ Supplementary Material.

\section{ETHICS STATEMENT}

All experiment involved human are approved by the Ethics Committee of Jiangsu Province Hospital. All participants agreed to participate this study and signed informed consent document at the time of enrollment. This study complied with the Helsinki Declaration.

\section{AUTHOR CONTRIBUTIONS}

SJ, PX, S-PM, NS, and KL conceived the study. NS, KL, HW, ML, $\mathrm{HM}$, and XX recruited the CS-AKI patients and collected clinical data. NS, XL, and LY reviewed eligible publications and extracted the data needed for the meta-analysis. NS, YF, and SZ performed statistical analysis. All authors contributed to the article and approved the submitted version.

\section{FUNDING}

This project funded by Jiangsu Provincial Science Foundation (Grant No. BK20190555) and the National Natural Science Foundation of China (Grant No. 81900780).

\section{SUPPLEMENTARY MATERIAL}

The Supplementary Material for this article can be found online at: https://www.frontiersin.org/articles/10.3389/fendo.2020. 534294/full\#supplementary-material

8. Hobson CE, Yavas S, Segal MS, Schold JD, Tribble CG, Layon AJ, et al. Acute kidney injury is associated with increased long-term mortality after cardiothoracic surgery. Circulation (2009) 119(18):2444-53. doi: 10.1161/ CIRCULATIONAHA.108.800011

9. Wang Y, Bellomo R. Cardiac surgery-associated acute kidney injury: risk factors, pathophysiology and treatment. Nat Rev Nephrol (2017) 13(11):697711. doi: 10.1038/nrneph.2017.119

10. Peitz GW, Troyer J, Jones AE, Shapiro NI, Nelson RD, Hernandez J, et al. Association of body mass index with increased cost of care and length of stay for emergency department patients with chest pain and dyspnea. Circulation Cardiovasc Qual Outcomes (2014) 7(2):292-8. doi: 10.1161/CIRCOUTCOMES.113.000702

11. BMI classification Electronic resource. World health organization. Available at: https://www.who.int/topics/obesity/en/. Title from the screen.

12. Amann K, Benz K. Structural renal changes in obesity and diabetes. Semin Nephrol (2013) 33(1):23-33. doi: 10.1016/j.semnephrol.2012.12.003

13. Glance LG, Wissler R, Mukamel DB, Li Y, Diachun CAB, Salloum R, et al. Perioperative outcomes among patients with the modified metabolic syndrome who are undergoing noncardiac surgery. Anesthesiology (2010) 113(4):859-72. doi: 10.1097/ALN.0b013e3181eff32e

14. Druml W, Metnitz B, Schaden E, Bauer P, Metnitz PG. Impact of body mass on incidence and prognosis of acute kidney injury requiring renal replacement 
therapy. Intensive Care Med (2010) 36(7):1221-8. doi: 10.1007/s00134-010$1844-2$

15. Thakar CV, Kharat V, Blanck S, Leonard AC. Acute kidney injury after gastric bypass surgery. Clin J Am Soc Nephrol CJASN (2007) 2(3):426-30. doi: 10.2215/CJN.03961106

16. Silver AE, Beske SD, Christou DD, Donato AJ, Moreau KL, Eskurza I, et al. Overweight and obese humans demonstrate increased vascular endothelial NAD (P)H oxidase-p47(phox) expression and evidence of endothelial oxidative stress. Circulation (2007) 115(5):627-37. doi: 10.1161/CIRCULATIONAHA. 106.657486

17. Greenberg AS, Obin MS. Obesity and the role of adipose tissue in inflammation and metabolism. Am J Clin Nutr (2006) 83(2):461S-5S. doi: 10.1093/ajcn/83.2.461S

18. Van Der Boon R, Chieffo A, Dumonteil N, Tchetche D, Van Mieghem N, Vahdat $\mathrm{O}$, et al. Effect of body mass index on short- and long-term outcomes after transcatheter aortic valve implantation. Am J Cardiol (2013) 111(2):231-6. doi: 10.1016/j.amjcard.2012.09.022

19. Jiang WH, Teng J, Xu JR, Shen YM, Wang Y, Fang ZP, et al. Dynamic Predictive Scores for Cardiac Surgery-Associated Acute Kidney Injury. J Am Heart Assoc (2016) 5(8):1-10. doi: 10.1161/JAHA.116.003754

20. Chen C, Lu FC. Department of Disease Control Ministry of Health PRC. The guidelines for prevention and control of overweight and obesity in Chinese adults. Biomed Environ Sci BES (2004) 17 Suppl:1-36.

21. Billings FT, Pretorius M, Schildcrout JS, Mercaldo FT, Byrne JG, Ikizler TA, et al. Obesity and oxidative stress predict AKI after cardiac surgery. J Am Soc Nephrol JASN (2012) 23(7):1221-8. doi: 10.1681/ASN.2011090940

22. Kumar AB, Bridget Zimmerman M, Suneja M. Obesity and postcardiopulmonary bypass-associated acute kidney injury: a single-center retrospective analysis. J Cardiothoracic Vasc Anesthesia (2014) 28(3):551-6. doi: 10.1053/j.jvca.2013.05.037

23. Zou ZP, Zhuang YM, Liu L, Shen B, Ding XQ, et al. Role of Body Mass Index in Acute Kidney Injury Patients after Cardiac Surgery. Cardiorenal Med (2017) 8(1):9-17. doi: 10.1159/000477824

24. Wigfield CH, Lindsey JD, Munoz A, Chopra PS, Edwards NM, Love RB. Is extreme obesity a risk factor for cardiac surgery? An analysis of patients with a BMI $>$ or $=40$. Eur J Cardio-thoracic Surg Off J Eur Assoc Cardio-thoracic Surgery (2006) 29(4):434-40. doi: 10.1016/j.ejcts.2006.01.016

25. O'Sullivan KE, Byrne JS, Hudson A, Murphy AM, Sadlier DM, Hurley JP. The effect of obesity on acute kidney injury after cardiac surgery. $J$ Thoracic Cardiovasc Surgery (2015) 150(6):1622-8. doi: 10.1016/j.jtcvs.2015.08.082

26. Rapetto F, Bruno VD, King M, Benedetto U, Caputo M, Angelini GD, et al. Impact of body mass index on outcomes following mitral surgery: does an obesity paradox exist? Interact Cardiovasc Thoracic Surgery (2018) 26(4):5905. doi: 10.1093/icvts/ivx383

27. Ko T, Higashitani M, Sato A, Uemura Y, Norimatsu T, Mahara K, et al. Impact of Acute Kidney Injury on Early to Long-Term Outcomes in Patients Who Underwent Surgery for Type A Acute Aortic Dissection. Am J Cardiol (2015) 116(3):463-8. doi: 10.1016/j.amjcard.2015.04.043

28. Reis C, Barbiero SM, Ribas L. The effect of the body mass index on postoperative complications of coronary artery bypass grafting in elderly. Rev Bras Cirurgia Cardiovasc orgao oficial da Sociedade Bras Cirurgia Cardiovasc (2008) 23(4):524-9. doi: 10.1016/j.pmn.2017.10.018

29. Roh GU, Lee JW, Nam SB, Lee J, Choi JR, Shim YH. Incidence and risk factors of acute kidney injury after thoracic aortic surgery for acute dissection. Ann Thorac Surg (2012) 94(3):766-71. doi: 10.1016/j.athoracsur.2012.04.057

30. Brown JR, Kramer RS, MacKenzie TA, Coca SG, Sint K, Parikh CR. Determinants of acute kidney injury duration after cardiac surgery: an externally validated tool. Ann Thoracic Surgery (2012) 93(2):570-6. doi: 10.1016/j.athoracsur.2011.11.004

31. Hsu RK, McCulloch CE, Ku E, Dudley RA, Hsu CY. Regional variation in the incidence of dialysis-requiring AKI in the United States. Clin J Am Soc Nephrol CJASN (2013) 8(9):1476-81. doi: 10.2215/CJN.12611212
32. Chagnac A, Weinstein T, Korzets A, Ramadan E, Hirsch J, Gafter U. Glomerular hemodynamics in severe obesity. Am J Physiol Renal Physiol (2000) 278(5):F817-822. doi: 10.1152/ajprenal.2000.278.5.F817

33. Chagnac A, Weinstein T, Herman M, Hirsh J, Gafter U, Ori Y. The effects of weight loss on renal function in patients with severe obesity. J Am Soc Nephrol JASN (2003) 14(6):1480-6. doi: 10.1097/01.ASN.0000068462.38661.89

34. Marik PE, Desai H. The emergent malignant obesity hypoventilation syndrome: a new critical care syndrome. Author reply. J Intensive Care Med (2013) 28(3):200. doi: 10.1177/0885066612464343

35. Marik PE, Desai H. Characteristics of patients with the "malignant obesity hypoventilation syndrome" admitted to an ICU. J Intensive Care Med (2013) 28(2):124-30. doi: 10.1177/0885066612444261

36. Danziger J, Chen KP, Lee J, Feng ML, Mukama KJ. Obesity, Acute Kidney Injury, and Mortality in Critical Illness. Crit Care Med (2016) 44(2):328-34. doi: 10.1097/CCM.0000000000001398

37. Medico CJ, Walsh P. Pharmacotherapy in the critically ill obese patient. Crit Care Clin (2010) 26(4):679-88. doi: 10.1016/j.ccc.2010.07.003

38. Mullens W, Abrahams Z, Francis GS, Taylor DO, Starling RC. Importance of venous congestion for worsening of renal function in advanced decompensated heart failure. J Am Coll Cardiol (2009) 53(7):589-96. doi: 10.1016/j.jacc.2008.05.068

39. Kim IB, Prowle J, Baldwin I, Bellomo R. Incidence, risk factors and outcome associations of intra-abdominal hypertension in critically ill patients. Anaesthesia Intensive Care (2012) 40(1):79-89. doi: 10.1177/0310057X1204000107

40. McGavock JM, Victor RG, Unger RH, Szczepaniak LS. American College of P, the American Physiological S. Adiposity of the heart, revisited. Ann Internal Med (2006) 144(7):517-24. doi: 10.7326/0003-4819-144-7-200604040-00011

41. Tobias DK, Hu FB. Does being overweight really reduce mortality? Obesity (2013) 21(9):1746-9. doi: 10.1002/oby.20602

42. Stamou SC, Nussbaum M, Stiegel RM, Reames MK, Skipper ER, Robicsek F, et al. Effect of body mass index on outcomes after cardiac surgery: is there an obesity paradox? Ann Thoracic Surgery (2011) 91(1):42-7. doi: 10.1016/ j.athoracsur.2010.08.047

43. Reeves BC, Ascione R, Chamberlain MH, Angelini GD. Effect of body mass index on early outcomes in patients undergoing coronary artery bypass surgery. J Am Coll Cardiol (2003) 42(4):668-76. doi: 10.1016/S0735-1097(03)00777-0

44. Johnson AP, Parlow JL, Whitehead M, Xu J, Rohland S, Milne B. Body Mass Index, Outcomes, and Mortality Following Cardiac Surgery in Ontario, Canada. J Am Heart Assoc (2015) 4(7):e002140. doi: 10.1161/JAHA.115.002140

45. Ghanta RK, LaPar DJ, Zhang Q, Devarkonda V, Isbell JM, Yarboro LT, et al. Obesity Increases Risk-Adjusted Morbidity, Mortality, and Cost Following Cardiac Surgery. J Am Heart Assoc (2017) 6(3):e003831. doi: 10.1161/JAHA.116.003831

46. Hong S, Youn YN, Yoo KJ. Metabolic syndrome as a risk factor for postoperative kidney injury after off-pump coronary artery bypass surgery. Circ J (2010) 74(6):1121-6. doi: 10.1253/circj.CJ-09-0842

47. Forni LG, Joannidis M. Blood pressure deficits in acute kidney injury: not all about the mean arterial pressure? Crit Care (2017) 21(1):102. doi: 10.1186/ s13054-017-1683-4

48. Venkatachalam MA, Weinberg JM, Kriz W, Bidani AK. Failed Tubule Recovery, AKI-CKD Transition, and Kidney Disease Progression. J Am Soc Nephrol (2015) 26(8):1765-76. doi: 10.1681/ASN.2015010006

Conflict of Interest: The authors declare that the research was conducted in the absence of any commercial or financial relationships that could be construed as a potential conflict of interest.

Copyright $\odot 2020$ Shi, Liu, Fan, Yang, Zhang, Li, Wu, Li, Mao, Xu, Ma, Xiao and Jiang. This is an open-access article distributed under the terms of the Creative Commons Attribution License (CC BY). The use, distribution or reproduction in other forums is permitted, provided the original author(s) and the copyright owner(s) are credited and that the original publication in this journal is cited, in accordance with accepted academic practice. No use, distribution or reproduction is permitted which does not comply with these terms. 